\title{
O BIOMA FLORESTAL COM ARAUCÁRIA E A LEGISLAÇÃO TRIBUTÁRIA BRASILEIRA
}

\author{
Paulo de Tarso de Lara Pires ${ }^{1}$, Edson Luiz Peters ${ }^{2}$, Douglas Magno Zeni ${ }^{3}$, Debora Gaulke ${ }^{4}$ \\ ${ }^{1}$ Eng. Florestal, Advogado, Dr., Depto. de Economia Rural e Extensão, UFPR, Curitiba, PR, Brasil - ptlpires@ufpr.br \\ ${ }^{2}$ Promotor de Justiça, Depto. de Direito Público, PUC-PR, Curitiba, PR, Brasil - elpeters@uol.com.br \\ ${ }^{3}$ Eng. Florestal, Especialista, Curitiba, PR, Brasil - dmzjr@hotmail.com \\ ${ }^{4}$ Eng ${ }^{a}$ Florestal, MBA Internacional em Gestão Ambiental, UFPR, Curitiba, PR, Brasil - debora.gaulke@ gmail.com
}

Recebido para publicação: 04/07/2008 - Aceito para publicação: 26/08/2010

\begin{abstract}
Resumo
Com a descoberta de novas tecnologias a partir dos séculos XIX e XX, um intenso processo de ocupação territorial se desencadeou, ocasionando uso desordenado dos recursos naturais e destruição de áreas verdes. O estado do Paraná possui atualmente menos de $10 \%$ de área florestal original, evidenciando a necessidade de se definirem novas políticas de desenvolvimento e conservação para as Florestas com Araucária. Dessa maneira, propõe-se a criação de instrumentos legais para incentivar o uso racional e o aumento da cobertura florestal com araucária no Paraná, mediante a adoção de novos critérios para a arrecadação de duas espécies tributárias: Imposto sobre Transmissão de Bens Imóveis (ITBI) e Imposto sobre Produtos Industrializados (IPI). Uma alternativa promissora está na adoção de novos programas de incentivo fiscal, destinados ao desenvolvimento do setor florestal e à proteção do meio ambiente. Adicionalmente, sugere-se a aplicação de uma alíquota progressiva para o ITBI, em função da qualidade e tamanho do remanescente que podem contribuir com maior efetividade na conservação e recuperação do bioma. Concomitantemente, a adoção de uma nova metodologia para o cálculo do valor do IPI exclusiva para artefatos de madeira forneceria subsídios para o desenvolvimento sustentável das florestas com araucária no Estado.

Palavras-chave: Floresta Ombrófila Mista; legislação; tributação.
\end{abstract}

\begin{abstract}
The use of brazilian tributary legislation on the araucaria forest biome. Throughout the discovery of new technologies during the 19th and 20th centuries, territorial occupation was triggered, causing the unsustainable use of natural resources and the destruction of green areas. The state of Parana, currently holds approximately 5\% of its original forest area, which highlights the necessity of developing new policies for development and conservation for the Araucaria Forest. Therefore, it is proposed to use legal economic instruments to encourage sustainable use and also aim towards increasing the Araucaria Forest cover in Parana. The economic instruments considered for use include: A tax on Transfer of Real Estate (ITBI) and a tax on Industrialized Products (IPI). The adoption of the new tax incentive programs in order to develop the forestry sector and protect the environment is a promising alternative to the more common forms of environmental regulation. Furthermore, it is suggested to apply a progressive rate for the ITBI, depending on the quality and size of the remaining forest which may contribute being greatly effective in the conservation and recovery of the biome. As result, the adoption of a new method for the calculation of the designated IPI level, exclusively for wood artifacts, should provide subsides for sustainable development of Araucaria forests in Parana.

Keywords: Araucaria Moist Forests; legislation; tax.
\end{abstract}

\section{INTRODUÇÃO}

Apesar da reconhecida importância das florestas e das fortes pressões de movimentos ambientalistas nacionais e internacionais, no Brasil os remanescentes foram e prosseguem sendo devastados. Esse processo, que ocorreu de forma intensa nas regiões Sul e Sudeste do país, teve seu auge na segunda metade do século passado e segue indomável na região amazônica. Tendo como bandeira a 
abertura de novas fronteiras agrícolas, a geração de novos empregos e o desenvolvimento social, espécies florestais preciosas vêm sendo dizimadas. Às dificuldades econômicas e sociais do país soma-se a dimensão territorial como fator dificultador da fiscalização e do estabelecimento de uma política nacional de desenvolvimento florestal.

A diversidade de tipologias florestais deve ser também considerada, possibilitando a criação de políticas próprias, adaptadas às realidades locais e às características diferenciadas de cada bioma. $\mathrm{Na}$ região Sul do país destaca-se o bioma Floresta com Araucária, por suas peculiares espécies e riqueza de recursos madeireiros. As Florestas com Araucária são um símbolo da região Sul, tanto pela importância econômica, com vultosos recursos gerados pela madeira e outros produtos da floresta, quanto pelo vínculo afetivo, incontestável para o seu povo.

O estado do Paraná, em particular, caracterizado pela predominância dessa tipologia, que, de acordo com Maack (1968), possuía cerca de $83 \%$ da superfície originalmente coberta por uma exuberante vegetação, hoje tem sua área florestal reduzida a pequena porção do território. Daí a necessidade de intensificar os estudos florestais no estado.

Considerando a significativa carga tributária que incide sobre as atividades agrícolas, silviculturais e industriais brasileiras, justifica-se o estudo de ferramentas fiscais para o incentivo ao desenvolvimento da atividade florestal de produção e de conservação da Floresta Ombrófila Mista. O exame desses dados é de suma importância para se encontrarem soluções e definirem políticas de desenvolvimento e conservação para as Florestas com Araucária no estado.

Este artigo objetiva fazer uma rápida explanação de conceitos fundamentais para a aplicação da ciência do Direito Tributário ao estudo do caso concreto. Partindo do binômio entre preservação e uso sustentável dos recursos naturais, e considerando o caráter extrafiscal dos tributos, propõe-se a criação de instrumentos legais para incentivar o uso racional e o aumento da cobertura florestal com araucária no Paraná, por meio da adoção de novos critérios para a arrecadação de duas espécies tributárias: Imposto sobre Transmissão de Bens Imóveis e Imposto sobre Produtos Industrializados, sobre os quais o trabalho passa a explanar.

\section{REVISÃO BIBLIOGRÁFICA}

"Tributo é toda prestação pecuniária compulsória, em moeda ou cujo valor nela se possa exprimir, que não constitua sanção de ato ilícito, instituída em lei e cobrada mediante atividade administrativa plenamente vinculada", conforme definição expressa no artigo $3^{\circ}$ do Código Tributário Nacional (CTN). Dessa definição pode se inferir que se trata de uma prestação obrigatória, mas não uma penalidade, estabelecida exclusivamente por lei, que deve ser quitada preferencialmente em moeda corrente do país.

O Sistema Tributário Nacional é formado pelo conjunto de normas jurídicas que regem todos os atos que se referem a tributos em território brasileiro. Bastos (1997) o define como um conjunto de elementos organizados de tal sorte que a alteração em um deles cause alteração no todo. Dá-se o nome de Sistema Tributário Nacional ao conjunto de normas agrupadas pelo conceito de tributo. O STN compõese da Constituição Federal, das leis complementares, das resoluções do Senado, das leis estaduais, das Constituições Estaduais e das leis municipais, entre outras regulamentações e disposições legais (CASTELANOS, 2002).

A doutrina brasileira, confirmada pela Constituição Federal Brasileira de 1988, acolhe a divisão tripartida dos tributos quando prevê que a União, os Estados, o Distrito Federal e os Municípios poderão instituir os seguintes tributos: impostos, taxas e contribuição de melhoria.

As taxas são os pagamentos feitos ao Estado decorrentes de uma vantagem que o Estado lhe oferece. Já a contribuição de melhoria é o pagamento feito ao Estado decorrente de uma obra pública que causou benefício ou valorização do imóvel. Por fim, os impostos são os pagamentos de certos valores decorrentes de um fato que os geram e os determinam.

\section{Experiência internacional}

Em países da União Europeia, a tributação ambiental é amplamente empregada, objetivando desestimular atividades poluidoras. A incidência de impostos sobre a produção e consumo de certos 
produtos poluidores, com isenção total ou parcial a outros não poluidores, tem sido instrumento de proteção ao meio ambiente.

Pichot e Rapado (1994) afirmam que, desde o final dos anos 80, as políticas ambientais ocupam uma posição de primeiro plano nas preocupações econômicas e políticas, já que os países da União Europeia deparam-se com um número crescente de problemas, como por exemplo a escassez de recursos para a manutenção das áreas protegidas.

$\mathrm{Na}$ Alemanha e na Bélgica, diferentes iniciativas têm sido tomadas objetivando a proteção dos recursos naturais. A União Europeia tem taxado pesadamente o consumo de combustíveis fósseis. Países como Dinamarca, Finlândia, Noruega, Países Baixos e Suécia têm aplicado impostos sobre a produção de carbono, com o objetivo principal de gerar recursos com finalidades de fomentar projetos na área ambiental (PICHOT; RAPADO, 1994).

Santos (1997) afirma que a França, no ano de 1996, possuía a maior área de cobertura florestal da Europa. O governo desenvolveu políticas de incentivo à atividade florestal por meio de isenções tributárias, que são classificadas em isenções relacionadas às florestas em geral, aos reflorestamentos e às áreas protegidas, em caráter total ou parcial.

Nos Estados Unidos, de acordo com Young e Shields (1996), o Food Security Act of 1985 (P.L. 99-198), promulgado em 23 de dezembro de 1985, e o Food, Agriculture, Conservation and Trade (Fact) Act of 1990 (P.L. 101-264), promulgado em 28 de novembro de 1990, serviram como referência para o desenvolvimento da política ambiental no meio rural americano.

Segundo Osborn (1997), a lei agrícola de 1985 trouxe transformações significativas para reduzir as contradições entre incentivos à produção agrícola e à conservação ambiental, além de ter incorporado novas medidas relativas à conservação dos recursos naturais.

O mesmo autor ainda afirma que uma das mais importantes iniciativas ambientais nos EUA é o Programa de Reserva para Conservação (CRP), que tem como objetivo principal reduzir a erosão e proteger a qualidade de água em cerca de 45 milhões de acres de terras agricultáveis, em que os produtores se comprometem a destinar terras de agricultura com alto risco de erosão ou ambientalmente sensíveis para usos mais adequados, num período de 10 a 15 anos. Como compensação os proprietários recebem pagamentos equivalentes ao arrendamento anual da área e participação do Departamento de Agricultura Americano (USDA) no custeio da conversão e manutenção do novo uso do solo. As regras do subsídio têm como base valores de arrendamento médios, em plano municipal, ajustados segundo fatores de produtividade do solo registrados no passado. A regra proposta utiliza probabilidade de erosão dos solos, qualidade de água e custo de implementação como componentes do índice.

$\mathrm{Na}$ Austrália e na Nova Zelândia, permite-se a transferência dos recursos ligados a uma parcela de terra com significância ecológica a outra parcela sem essa característica. Dessa forma, o proprietário do terreno de importância ambiental recebe recursos para a manutenção e o desenvolvimento do local de um empreendedor que deseja realizar uma obra num local crítico para implantação. Essa política tem sido empregada principalmente em regiões próximas às grandes metrópoles, para preservar os remanescentes de floresta nativa, e em áreas agrícolas, na preservação de habitats de vital importância (NICHOLAS, 1991).

No caso do Uruguai, Platero (1996) afirma que a atividade teve um grande impulso com a Lei $\mathrm{n}^{\mathrm{o}} 15.939$, de 1987, que constitui o instrumento central da política florestal do país, com dois grandes pilares: subsídio ao reflorestamento e isenção fiscal. A política florestal estabelecida a partir dessa lei veio a aumentar, rapidamente, a área florestal plantada. Paralelamente, foi criado o Fundo Florestal, com recursos que se destinam prioritariamente a custear em até $50 \%$ o estabelecimento de áreas florestais por empresas privadas. O autor conclui que a política promoveu, entre 1989 a 1994, incremento superior a 125.000 ha na área florestal do país.

No Paraguai, em 1973, entrou em vigor a Lei no 422, que criou o Serviço Florestal Nacional, fixando seus objetivos e sua jurisdição, e implantou o regime florestal do país e o regime de aproveitamento florestal. Também o Decreto $\mathrm{n}^{\circ} 11.681 / 75$ estabeleceu o marco para a implementação de mecanismos de incentivo ao reflorestamento. Finalmente, a Lei $\mathrm{n}^{\circ} 536 / 95$, de fomento ao reflorestamento, constitui a base para impulsionar a atividade florestal no Paraguai, prevendo mecanismos fiscais e tributários que permitem incentivar e fomentar essa atividade pouco tradicional no país (PINAZZO, 1996). 
Na Argentina, duas leis recentes surgiram com o propósito de garantir a preservação dos remanescentes de florestas nativas. Essas leis criaram um sistema de incentivos aos estabelecimentos privados que cumprem as técnicas de manejo adequadas, da seguinte forma:

a) Lei Provincial de Áreas Protegidas (Lei $n^{\circ}$ 2.932/93): os estabelecimentos que conservarem floresta nativa em mais de $30 \%$ da área recebem desconto de até $60 \%$ no Imposto Imobiliário Provincial. Para zonas críticas, esse benefício pode chegar a $80 \%$. São excluídas desse regime as terras de uso agrícola, criação de gado e com monoculturas florestais.

b) Lei Provincial $n^{\circ} 3.041$ (Decreto $n^{\circ}$. 2.472/93): cria a Reserva da Biosfera Yabotí, na qual as áreas privadas localizadas dentro da Reserva obtêm isenção total do pagamento do Imposto Imobiliário Provincial.

\section{Experiência nacional}

A Lei $n^{\circ} .8 .171$, de 1.991, Lei da Política Agrícola Nacional, estabelece incentivos especiais aos proprietários rurais que preservarem e conservarem a cobertura florestal nativa existente nas propriedades. Os incentivos dessa Lei (art.103) são, entre outros, a prioridade da obtenção de apoio financeiro oficial, mediante a concessão de crédito rural e outros tipos de financiamento, bem como a cobertura de seguro agrícola concedido pelo Poder Público; o fornecimento de mudas de espécies nativas para recompor a cobertura florestal; e apoio técnico-educativo no desenvolvimento de projetos de preservação, conservação e recuperação ambiental.

Outro benefício estabelece a isenção do Imposto Territorial Rural para as áreas de preservação permanente e de reserva legal, previstas na Lei $n^{\circ}$ 4.771/65 (art.18 e 39), alterada pela MP 2.166-67/2001, no Estatuto da Terra, Lei $\mathrm{n}^{\circ} .4 .504$ de 1964 (art. 50, $\$ 8^{\circ}$.), estendidas às áreas de propriedade rural de interesse ecológico para a proteção de ecossistemas (art. $10^{\circ}$ da Lei 9.393/96, com a redação dada pela Lei 11.428/2006).

Programa Federal de Incentivos Fiscais ao Florestamento e Reflorestamento

A primeira iniciativa de incentivo ao florestamento e reflorestamento foi instituída pela Lei $\mathrm{n}^{\circ}$ $4.771 / 65$, art. 38, que determinava que as florestas plantadas ou naturais eram imunes a qualquer tributação e que não poderiam determinar, para efeito tributário, aumento do valor das terras em que se encontram. O parágrafo primeiro desse artigo determinava que não seria considerada renda tributável o valor de produtos florestais obtidos em florestas plantadas, por quem as houvesse formado. A Lei $\mathrm{n}^{\circ}$ 5.106/66 revogou esse artigo e propôs um programa de incentivo às atividades silviculturais, com o objetivo principal de incrementar a área de reflorestamentos no país, para abastecer as indústrias de papel e celulose e as siderurgias de carvão vegetal. O Decreto-Lei $\mathrm{n}^{\circ} 1.134$, de 16 de novembro de 1970, regulamentou a Lei descrita, permitindo que a pessoa jurídica pudesse optar por alocar até $50 \%$ do Imposto de Renda devido para ser aplicado em empreendimentos florestais.

Em seguida, a Lei $n^{\circ} 5.106 / 66$, artigos $1^{\circ}\left(\S 1^{\circ}\right)$ e $2^{\circ}$, reduziu as dimensões do incentivo, transformando-o em abatimento da renda bruta, submetendo-o ao limite e às condições das leis $\mathrm{n}^{\circ}$ $4.506 / 64$ (art. $9^{\circ}$ ) e 4.357/64 (art. $14, \S 2^{\circ}$ ) e condicionando-o às mesmas exigências então fixadas para as pessoas jurídicas ${ }^{1}$. O limite para que a pessoa física abatesse em sua declaração os gastos com reflorestamento era de $50 \%$ da renda bruta, mas tratava-se de um limite global para a somatória de numerosos abatimentos, tais como: aplicações em diversos investimentos (parcelas admitidas de aplicações em títulos da dívida pública federal, em ações nominativas de certas Sociedades Anônimas, em determinados depósitos e letras hipotecárias, em ações nominativas de algumas empresas etc.), despesas de instrução, juros de dívidas pessoais, juros do Sistema Financeiro da Habitação, prêmios de seguros de vida e de acidentes pessoais, contribuições e doações a instituições filantrópicas etc. O Decreto-Lei $\mathrm{n}^{\mathrm{o}} 1.841 / 80$ revogou a possibilidade de incluir as despesas com florestamento e reflorestamento.

Prado (1990) pesquisou os mecanismos utilizados e os recursos aplicados e avaliou os impactos do programa sobre o setor florestal, concluindo que durante o período de vigência do programa o país teve um grande incremento na quantidade de área reflorestada.

\footnotetext{
${ }^{1}$ O projeto seria aprovado pelo Ministério da Agricultura, obedecendo a condições mínimas, em terras de que se tivesse justa posse, visando à exploração econômica e conservação do solo e do regime de águas.
} 
Programa de Incentivo ao Reflorestamento em Pequenos e Médios Imóveis Rurais (REPEMIR)

Programa criado em 1974, período em que o Ministério de Minas e Energia incentivava alguns setores da economia a substituir, quando possível, os processos de obtenção de energia com o uso de derivados de petróleo pelo uso da lenha ou carvão vegetal. Com recursos advindos do Conselho Nacional do Petróleo, o extinto Instituto Brasileiro de Desenvolvimento Floresta (IBDF) criou um programa baseado em créditos subsidiados. O objetivo do programa era o de aumentar a oferta de lenha e carvão vegetal, além de fornecer ao pequeno e médio proprietário rural madeira para ser utilizada em sua propriedade, refletindo positivamente sobre a economia e o meio ambiente.

Bacha (1995) afirma que o programa foi implantado no estado de São Paulo no ano de 1978, vigorando durante cinco anos. Consistia na concessão de $100 \%$ de financiamento para a realização de plantios de no máximo 20 ha em propriedades de até 300 ha. De acordo com relatório do IPEA/COMIF, citado por Bacha (1995), os recursos repassados do Conselho Nacional do Petróleo para o REPEMIR resultaram na implantação de 80 a 100 mil ha de florestas, representando apenas 1,8\% da área total de reflorestamentos incentivados.

ICMS Ecológico (Lei Complementar do Estado do Paraná no 59/91)

O Imposto sobre Circulação de Mercadorias e sobre Prestação de Serviços de Transporte Interestadual, Intermunicipal e de Comunicação (ICMS) tem como hipótese de incidência/fato gerador a venda de mercadorias ou serviços feita por produtor, comerciante, industrial ou pessoas a eles equiparadas e o ingresso em estabelecimentos comerciais, industriais ou produtores de mercadorias importadas (FOERSTER, 1991).

Através da Lei Complementar $n^{\circ}$ 59/91, o Paraná criou uma metodologia de repartição dos recursos gerados pelo ICMS que privilegia os municípios com áreas de significativa importância ecológica. O benefício veio do repasse de $5 \%$ dos $25 \%$ da arrecadação do ICMS destinados ao Fundo de Participação dos Municípios, que são rateados proporcionalmente ao grau de importância ambiental de cada um dos municípios cadastrados e contemplados pela disposição da lei dos royalties ecológicos. A lei dispõe que são contemplados os municípios que abrangerem em seu território unidades de conservação ambiental, ou que sejam influenciados por elas ou ainda com mananciais de abastecimento público.

\section{MATERIAL E MÉTODOS}

O trabalho busca, através de estudos doutrinários e jurisprudenciais, subsídios para arquitetar uma estratégia fiscal/ambiental para a preservação dos remanescentes do bioma Floresta com Araucária.

O trabalho propõe alternativas de incentivo tributário em prol da proteção dos remanescentes da Floresta com Araucária com base na análise de experiências nacionais e internacionais. As alternativas são: Imposto sobre a Transmissão de Bens Imóveis, Imposto sobre a Transmissão Bens Intervivos (ITBI) e Imposto sobre Produtos Industrializados (IPI). Foi necessário criar uma metodologia para o estabelecimento de alíquotas diferenciadas, bem como instituir um novo critério para a fixação de alíquotas com base nos princípios do poluidor-pagador e protetor-beneficiário. Como demonstrado a seguir, uma metodologia para o estabelecimento de alíquotas diferenciadas é proposta, a fim de desestimular a manutenção de propriedades com baixa cobertura florestal e de estimular a melhoria da qualidade das florestas. Sua construção foi alicerçada sobre os princípios constitucionais da função social da propriedade rural, razoabilidade e proporcionalidade e em princípios específicos do Direito Ambiental, tais como o princípio da precaução e do protetor-beneficiário.

Para aplicação do modelo ao caso concreto, foram selecionadas, aleatoriamente, doze propriedades, situadas em 10 municípios paranaenses, inseridos no bioma Floresta com Araucária, que apresentam situações distintas em relação ao tamanho da área, percentagem de cobertura florestal, valor venal do hectare e classes de floresta.

Em um segundo momento, é proposto um novo critério para a fixação de alíquota, especificamente para artefatos obtidos a partir de madeira proveniente da Floresta com Araucária, inseridos no capítulo 94 do Decreto 2.092/1996, que traz a tabela de alíquotas do Imposto sobre Produtos Industrializados. Para tanto, foi necessária a construção de dois novos institutos, o selo de controle de produtos de madeira e uma tabela de classificação de artefatos de madeira, considerando a origem da matéria-prima do produto. 


\section{RESULTADOS E DISCUSSÃO}

\section{Alternativas de incentivo tributário à preservação dos remanescentes do bioma florestal com araucária}

Imposto sobre Produtos Industrializados (IPI) e Imposto sobre Transmissão de Bens Imóveis, sendo este desdobrados em outros dois: Imposto Sobre a Transmissão de Bens Intervivos (ITBI) e Imposto sobre Transmissão Causa Mortis e Doação de Quaisquer Bens ou Direitos (ITCMD).

O imposto sobre a transmissão de bens imóveis

Como ensina Baleeiro (2002), a conceituação utilizada para definir os vários bens imóveis é oriunda do Código Civil, do qual destacamos:

a) imóveis por natureza: englobam o solo com a sua superfície, os seus acessórios e adjacências naturais, compreendendo as árvores e frutos pendentes, o espaço aéreo e o subsolo;

b) imóveis por acessão física: incluem tudo quanto o homem incorporar permanentemente ao solo, como a semente lançada à terra, os edifícios e construções, de modo que não se possa retirar sem destruição, modificação, fratura ou dano;

c) direitos reais sobre imóveis: são a enfiteuse ou aforamento, as servidões, o usufruto e o uso, a habitação e as rendas expressamente constituídas sobre o imóvel.

O Imposto sobre Transmissão Causa Mortis e Doação de Quaisquer Bens ou Direitos (ITCMD)

Conforme a obra de Baleeiro (2002), o imposto sobre transmissão causa mortis e doação de quaisquer bens ou direitos (ITCMD) foi instituído pelo Estado no século XIX, por meio do "selo de herança", através do Alvará de 1809, transformado posteriormente no "imposto de herança e legados", que após profundas mudanças originou o presente tributo.

De acordo com o art. $1^{\circ}$ da Instrução Normativa da Secretaria Estadual da Fazenda - ITCMD $\mathrm{n}^{\circ} 01 / 89$, esse imposto tem como principal hipótese de incidência ou fato gerador a transmissão por causa de morte e a doação (fatos não onerosos) de quaisquer bens, sejam móveis ou imóveis. Mais especificamente, as transmissões por causa de morte se dão pela transferência do domínio e da posse dos bens do de cujo, pela abertura da sucessão aos herdeiros legítimos e testamentários.

No que se refere à competência administrativa e legislativa, a Constituição Federal de 1988 incumbe aos Estados e ao Distrito Federal a administração desse imposto, inclusive as atividades de arrecadação, tributação e fiscalização.

O artigo 12 da Lei $\mathrm{n}^{\circ} 8.927 / 88$ dispõe que a alíquota do imposto é de $4 \%$ para qualquer transmissão. Como previsto no art. 13 e seguintes da lei, a base de cálculo para o lançamento e cobrança do ITCMD é o valor venal dos bens ou direitos ou o valor do título ou crédito, transmitidos ou doados, apurados mediante avaliação procedida pela Fazenda Pública Estadual, tomada por base a declaração formalizada pelo contribuinte. Nas doações com reserva de usufruto ou na sua instituição gratuita a favor de terceiros, o valor dos direitos reais do usufruto, uso ou habitação, vitalício ou temporário, será igual à metade do valor total do bem, correspondendo o valor restante à sua propriedade separada daqueles direitos.

Conforme disposto no art. $6^{\circ}$ da Lei $n^{\circ} 8.927 / 88$, são solidariamente responsáveis pelo imposto devido pelo contribuinte os tabeliães, escrivães e demais serventuários. Também são corresponsáveis as empresas, instituições financeiras e bancárias e todos aqueles a quem caiba a responsabilidade do registro ou a prática de ato que implique a transmissão de bem móvel ou imóvel e respectivos direitos e ações. Interessante tal dispositivo, na medida em que corresponsabiliza outros sujeitos que, participando do processo de transmissão, podem auxiliar na fiscalização e implementação do caráter extrafiscal do ITCMD.

Imposto sobre a Transmissão Bens Intervivos (ITBI)

O Artigo 156 da Constituição Federal determina que compete aos municípios criar impostos sobre a transmissão intervivos, a qualquer título oneroso, de bens imóveis. O município de Curitiba regulamentou esse tributo mediante a edição da Lei Complementar $n^{\circ}$ 40/2001, Capítulo III, intitulado: Do Imposto sobre a Transmissão Inter Vivos de Bens Imóveis. 
A Lei Complementar $n^{\circ}$ 40/2001 dispõe que o ITBI tem como hipóteses de incidência a transmissão "intervivos", a qualquer título, por ato oneroso, da propriedade ou do domínio útil de bens imóveis, por natureza ou acessão física, como definido na lei civil; e a transmissão "intervivos", a qualquer título, por ato oneroso, de direitos reais sobre imóveis, exceto os direitos reais de garantia e a cessão de direitos relativos à transmissão de bens (art. 47). $\mathrm{O}$ art. 48 dessa lei complementar reza que o sujeito passivo daquele imposto é o adquirente dos bens ou direitos, podendo ainda ser atribuída a condição de responsável ao vendedor ou ao cessionário dos bens ou direitos.

Compete aos municípios a administração desse imposto, inclusive as atividades de arrecadação, tributação e fiscalização, conforme a Constituição Federal de 1988.

De acordo com a Lei Complementar $n^{\circ}$. 40/2001, o ITBI é calculado com base no valor de avaliação do imóvel, aplicando-se uma alíquota de $2 \%$ sobre a mesma. A base imponível do imposto é o valor venal dos bens ou direitos transmitidos ou cedidos.

Finalmente, assim como na outra espécie tributária, a legislação criou, através do art. 52, uma forma externa de controle, que indubitavelmente será fundamental para a implementação do caráter extrafiscal desse tributo, eis que, para a transcrição do título de transferência no Registro de Imóveis, é obrigatório comprovar o pagamento do ITBI.

Outro objetivo da tributação serve para estimular ou desestimular certos comportamentos do contribuinte. Essa função é denominada extrafiscalidade, ou seja, o emprego dos meios tributários para fins não fiscais, objetivando disciplinar comportamentos da sociedade, estimulando atitudes benéficas ou coibindo atividades nocivas. O tributo passa a exercer preponderantemente um objetivo econômico e social, indispensável à estrutura do próprio Estado, seja como instrumento regulador de produção, seja como reagente à repartição de riquezas.

O Estado, no exercício da política extrafiscal do ITBI, poderá incentivar a ampliação das áreas verdes nos imóveis mediante a redução da alíquota para determinadas áreas com alta porcentagem de cobertura florestal, na aplicação do critério de regressividade. Poderá dificultar a manutenção e transmissão de áreas com baixa cobertura vegetal, onerando, por meio de pesadas alíquotas, aquelas propriedades que não mantêm sequer a reserva legal, prevista na legislação em vigor, na aplicação de critérios de progressividade.

De acordo com a proposta ora apresentada, o ITBI passa a ser um imposto que, em parte, terá o caráter fiscal e, em parte, o caráter extrafiscal, como instrumento para impelir o proprietário a promover a preservação e recuperação das áreas com cobertura florestal no bioma.

Proposta de metodologia para o estabelecimento de alíquotas diferenciadas

Da análise do problema, optou-se por uma metodologia aplicável às duas espécies do gênero Imposto sobre Transmissão de Bens Imóveis, incidente especificamente sobre imóveis rurais. Tal opção deve-se ao fato de que, apesar de serem de competência de diferentes esferas da Federação, ambos apresentam alíquota fixa, com base de cálculo semelhante. As alíquotas propostas para ambos graduar-seão com o objetivo de desestimular a manutenção de propriedades com baixa cobertura florestal e de estimular a melhoria da qualidade das florestas.

Para tanto, partiu-se da alíquota atual para um cenário desejado, exposto a seguir. No caso em estudo, a menor alíquota do Imposto sobre Transmissão Causa Mortis situa-se em 0,001, e a maior encontra-se no patamar de 0,14 , em função do grau de ocupação florestal e de acordo com a qualidade da floresta, como pode ser observado na tabela 1. Com relação ao Imposto sobre Transmissão de Móveis Intervivos, as alíquotas variam de 0,10 (máxima) a 0,001 (mínima).

Partindo dessa base de cálculo, esta pesquisa sugere critérios para a determinação do tributo a ser recolhido pelo contribuinte, que são os seguintes:

a) progressividade em relação à quantidade: quando o conjunto de informações analisadas e extraídas de ficha cadastral demonstra o uso inadequado, com baixa cobertura florestal;

b) progressividade em relação à qualidade: quando os referidos elementos indicarem a pior qualidade do remanescente florestal da propriedade.

O grau de cobertura florestal (GCF) é a relação percentual entre a área coberta por floresta nativa na propriedade e a área que pode ser efetivamente mantida com floresta, denominada área florestável. Essa área é obtida por meio da fórmula a seguir transcrita, que considera a área total, subtraída das áreas 
com benfeitorias, áreas com rios e áreas inaproveitáveis (alta pedregosidade, solo estéril, com alta acidez ou salinidade), devidamente vistoriadas.

$$
\mathrm{GCF}=\frac{\text { área efetivamente com floresta X } 100}{\text { área florestável }}
$$

Para os imóveis que apresentem grau de cobertura florestal inferior a $20 \%{ }^{2}$, a alíquota será multiplicada por coeficientes de progressividade. Para áreas com cobertura florestal superior a $20 \%$, haverá uma regressividade da alíquota.

Um segundo fator é a qualidade da floresta, a qual obedece ao critério estabelecido na Resolução 002/94 do CONAMA sobre licenciamento de exploração de floresta nativa no estado do Paraná. Esse documento classifica a floresta em Vegetação Primária, ao referir-se à vegetação que não foi afetada significativamente em suas características originais de estrutura e florística, e em Vegetação Secundária, em três estágios de sucessão, denominados Estágio Inicial, Estágio Médio e Estágio Avançado.

Para essa metodologia, consideram-se incluídas na classe 1 as propriedades com predominância de vegetação secundária em estágio inicial; na classe 2 aquelas com predominância de vegetação secundária em estágio médio; na classe 3 aquelas com predominância de vegetação secundária em estágio avançado; e, finalmente, na classe 4 aquelas com predominância de vegetação primária.

Tabela 1. Alíquotas sugeridas para o IBTI e ITCMD.

\begin{tabular}{|c|c|c|c|c|c|c|}
\hline \multirow{2}{*}{$\begin{array}{l}\text { Qualidade da floresta } \\
\text { conforme vegetação }\end{array}$} & \multicolumn{6}{|c|}{ Grau de cobertura florestal (em \%) } \\
\hline & $<\mathbf{1 0}$ & $>10 \mathrm{e}<20$ & 20 & $>20$ e $<50$ & $>50$ e $<80$ & $>80$ \\
\hline \multicolumn{7}{|c|}{ Imposto sobre Transmissão de Imóveis Causa Mortis - ITCMD } \\
\hline Classe 1 & 0.14 & 0.09 & 0.04 & 0.0347 & 0.0294 & 0.004 \\
\hline Classe 2 & 0.12 & 0.08 & 0.04 & 0.0277 & 0.0153 & 0.003 \\
\hline Classe 3 & 0.10 & 0.07 & 0.04 & 0.0273 & 0.0147 & 0.002 \\
\hline Classe 4 & 0.09 & 0.06 & 0.04 & 0.0270 & 0.0140 & 0.001 \\
\hline \multicolumn{7}{|c|}{ Imposto sobre Transmissão de Bens Imóveis Intervivos - ITBI } \\
\hline Classe 1 & 0.10 & 0.05 & 0.02 & 0.0147 & 0.0094 & 0.004 \\
\hline Classe 2 & 0.08 & 0.04 & 0.02 & 0.0143 & 0.0087 & 0.003 \\
\hline Classe 3 & 0.06 & 0.03 & 0.02 & 0.0140 & 0.0080 & 0.002 \\
\hline Classe 4 & 0.05 & 0.02 & 0.02 & 0.0137 & 0.0073 & 0.001 \\
\hline
\end{tabular}

Table 1. Suggested aliquots for the IBTI and ITCMD.

Para obter o valor do ITBI e do ITMCD, multiplica-se o valor venal do imóvel pela alíquota estabelecida na tabela 1 .

Através dessa metodologia o que ocorre é apenas uma compensação financeira. A isenção da parcela das propriedades rurais que possuem grande parte de sua área coberta por florestas será balanceada pela majoração no pagamento do tributo daquelas propriedades que possuem área de cobertura florestal abaixo do mínimo legal permitido.

O modelo proposto aplicado ao caso concreto em 10 municípios paranaenses permitiu vislumbrar o provável resultado na hipótese de ser adotado o exemplo sugerido no trabalho, como pode ser observado na tabela 2.

Observa-se que o modelo mantém uma consistência conceitual. Propriedades como a Fazenda Alegreti, que tem $20 \%$ de sua área como reserva legal, manteriam suas características atuais. Propriedades com alto grau de cobertura e com florestas com qualidade, como por exemplo a Fazenda Monte Sião, seriam efetivamente beneficiadas pela presente metodologia. Por outro lado, propriedades com baixo grau de cobertura sofreriam uma majoração na possível carga tributária, tal como a Fazenda do Barão.

\footnotetext{
${ }^{2}$ O limite de $20 \%$ tem como base o Código Florestal, que dispõe sobre a Reserva Legal e prevê:

"Art.16 - As florestas de domínio privado, não sujeitas ao regime de utilização limitada e ressalvadas as de preservação permanente, previstas nos artigos 2 e 3 desta lei, são suscetíveis de exploração, obedecidas as seguintes restrições:

a) nas regiões Leste Meridional, Sul e Centro-Oeste, esta na parte sul, as derrubadas de florestas nativas, primitivas ou regeneradas, só serão permitidas desde que seja, em qualquer caso, respeitado o limite mínimo de $20 \%$ da área de cada propriedade com cobertura arbórea localizada, a critério da autoridade competente; (...)".
} 
Tabela 2. Aplicação do modelo.

Table 2. Model application.

\begin{tabular}{lcccccccc}
\hline Nome - Local & $\begin{array}{c}\text { Tamanho } \\
(\mathbf{h a})\end{array}$ & $\begin{array}{c}\text { Valor } \\
\text { venal } \\
\mathbf{R} \$\end{array}$ & $\begin{array}{c}\text { Florestas } \\
\mathbf{( \% )}\end{array}$ & Classe & $\begin{array}{c}\text { Valor } \\
\text { atual }\end{array}$ & $\begin{array}{c}\text { Valor } \\
\text { ITCMD } \\
\text { R\$ }\end{array}$ & $\begin{array}{c}\text { Valor } \\
\text { atual }\end{array}$ & $\begin{array}{c}\text { Valor } \\
\text { ITBI } \\
\text { R\$ }\end{array}$ \\
\hline $\begin{array}{l}\text { Fazenda Alegreti } \\
\text { (Palmas) }\end{array}$ & 320 & 3.200 .000 & 20 & 4 & 128.000 & 128.000 & 64.000 & 64.000 \\
$\begin{array}{l}\text { Fazenda do Barão (Assis } \\
\text { Chateubriand) }\end{array}$ & 100 & 1.800 .000 & 7 & 2 & 72.000 & 216.000 & 36.000 & 144.000 \\
$\begin{array}{l}\text { Fazenda Assungui (Três } \\
\text { Barras) }\end{array}$ & 50 & 300.000 & 16 & 3 & 12.000 & 21.000 & 6.000 & 9.000 \\
$\begin{array}{l}\text { Fazenda Monte Castelo } \\
\text { (Palotina) }\end{array}$ & 320 & 5.800 .000 & 2 & 2 & 232.000 & 464.000 & 116.000 & 232.000 \\
$\begin{array}{l}\text { Fazenda Rio Novo } \\
\text { (Guarapuava) }\end{array}$ & 500 & 5.000 .000 & 32 & 2 & 2000.000 & 138.500 & 100.000 & 71.500 \\
$\begin{array}{l}\text { Fazenda Monte Sião } \\
\text { (Turvo) }\end{array}$ & 1.350 & 10.800 .000 & 82 & 4 & 432.000 & 10.800 & 216.000 & 10.800 \\
$\begin{array}{l}\text { Fazenda Cristo Redentor } \\
\text { (Turvo) }\end{array}$ & 6.000 & 54.000 .000 & 54 & 3 & 2.160 .000 & 793.800 & 1.080 .000 & 432.000 \\
$\begin{array}{l}\text { Fazenda Rio das Antas } \\
\text { (General Carneiro) }\end{array}$ & 850 & 8.500 .000 & 38 & 2 & 340.000 & 325.450 & 170.000 & 121.550 \\
$\begin{array}{l}\text { Fazenda Toca Fundo } \\
\text { (Irati) }\end{array}$ & 430 & 2.800 .00 & 43 & 1 & 112.000 & 97.160 & 56.000 & 41.160 \\
$\begin{array}{l}\text { Haras Três Palmeiras } \\
\text { (Ponta Grossa) }\end{array}$ & 90 & 850.000 & 12 & 4 & 34.000 & 51.000 & 17.000 & 17.000 \\
$\begin{array}{l}\text { Fazenda Bela Vista } \\
\text { (Telêmaco Borba) }\end{array}$ & 430 & 2.580 .000 & 27 & 1 & 103.200 & 89.526 & 51.600 & 37.926 \\
\hline
\end{tabular}

O imposto sobre produtos industrializados (IPI)

Esse imposto, após diversas modificações de leis e decretos, tem seus parâmetros atualmente estabelecidos na Constituição Federal de 1988 e em normas infraconstitucionais, como o Código Tributário Nacional e o Decreto-Lei no $87.981 / 1982$.

Atinge artigos classificados como de consumo, a exemplo de bebidas, fósforos e vestuários, e ao mesmo tempo mercadorias duráveis, bens de produção e coisas de duração indefinida. A obrigação tributária surge com a saída do produto do estabelecimento onde sofreu o processo de industrialização ou na entrada de produtos industriais estrangeiros.

De acordo com o disposto no artigo 46 do CTN, o IPI tem como hipótese de incidência a saída do estabelecimento industrial, o desembaraço aduaneiro de produtos industrializados, quando de procedência estrangeira, ou a sua arrematação, quando apreendido ou abandonado e levado para leilão. $\mathrm{O}$ mesmo dispositivo reza que são considerados industrializados os produtos que tenham sido submetidos a qualquer operação que lhes modifique a natureza, a finalidade, ou o aperfeiçoe para consumo, mediante a transformação da matéria-prima, beneficiamento, montagem, acondicionamento ou reacondicionamento de produto novo e renovação ou recondicionamento de produto usado.

De acordo com os ensinamentos de Vieira (1993), o contribuinte do IPI é toda pessoa natural ou jurídica de direito público ou privado que, direta ou indiretamente (por substituição), seja obrigada ao pagamento do tributo. $\mathrm{O}$ mesmo autor explica que o sujeito passivo é aquele situado no polo negativo da relação jurídica, a quem cabe a prestação pecuniária, devida ao sujeito ativo, a qual ocupa o polo positivo, sendo, no IPI, a pessoa jurídica de direito público titular da competência para exigir o cumprimento da obrigação.

A base de cálculo do IPI é diversa, dependendo sempre da hipótese de incidência. A variação é resultado da seletividade desse imposto, que possibilita que produtos essenciais tenham uma alíquota menor e produtos supérfluos tenham elevadas alíquotas, isso controlado pela tabela do IPI, elencada no Decreto-Lei $\mathrm{n}^{\circ} 1.767 / 95$. No caso de produto industrializado, utiliza-se o valor da operação, de acordo com o art. 47, II, da CTN. Quando se tratar de mercadoria importada, aplica-se a base do imposto de importação, acrescido dos impostos e eventuais encargos cambiais. Para produtos adquiridos em leilão, a base de cálculo é o valor arrematado. 
Com relação à imunidade ou às isenções tributárias que incidam no IPI, faz-se menção ao art. 153, parágrafo 3, III, da Constituição Federal de 1988, que estabelece vedação à incidência desse imposto sobre produtos industrializados que vão para o exterior. Ainda, a regra do art. 150, VI e VII, da Constituição veda a incidência do IPI em livros, jornais, pessoas jurídicas de direito público, autarquias e sobre produtos relacionados ao patrimônio.

O princípio da seletividade em função da essencialidade do produto é previsto no artigo 153, $\S 3^{\circ}$, IV, da Constituição Federal de 1988. Esse princípio está vinculado à capacidade contributiva da pessoa, ou seja, o requinte do consumo de uma pessoa conduz à ideia de maior capacidade contributiva. Por outro lado, o consumo de produtos básicos ou essenciais leva a deduzir uma menor disponibilidade de recursos (VIEIRA, 1993).

Para o desenvolvimento de uma nova metodologia de arrecadação, podem ser consideradas duas possibilidades de aplicação da seletividade em relação à essencialidade do produto, conforme assevera Vieira (1993). A primeira é variar a base de cálculo, mantendo fixa a alíquota; a segunda, ao contrário, seria oscilar as alíquotas e fixar a base de cálculo.

O princípio da seletividade realiza-se pelo estabelecimento das alíquotas na razão inversa da necessidade dos produtos. Quanto mais imprescindíveis os produtos para satisfazer as necessidades básicas da população, e, portanto, quanto mais essenciais, tanto menores deverão ser suas alíquotas de IPI, assegurando-lhes um tratamento brando e suave; de forma oposta, quanto menos indispensáveis os produtos, ou seja, menos essenciais, tanto maiores deverão ser suas alíquotas de IPI.

Vale observar que nada mais essencial que o meio ambiente equilibrado, subsídio fundamental para a manutenção da vida, direito maior tutelado pela Constituição Federal de 1988, em seu art. 225.

Na situação específica do Paraná, um estado com tradição silvicultural e atualmente o maior exportador brasileiro de madeira processada, propõe-se nessa etapa do trabalho uma política de incentivo fiscal ao uso racional dos recursos florestais como pilar para o incremento do mercado de trabalho e, consequentemente, como uma das ferramentas para assegurar o bem-estar social.

Proposta de criação do selo de controle de produtos de madeira oriunda do bioma florestal com araucária e de alteração da alíquota do IPI para esses produtos

A criação de um selo que controle o produto desde sua origem até o consumidor final se mostra como uma alternativa interessante para o incentivo à produção de forma sustentável e para coibir o consumo de matéria-prima sem controle de origem.

Estarão sujeitos a obter o selo os fabricantes dos produtos que utilizam madeira oriunda de florestas localizadas no Bioma Florestal com Araucária. A concessão do registro será dada ao estabelecimento fabricante de acordo com o tipo de atividade desenvolvida, sendo que um mesmo estabelecimento poderá ter dois tipos de registro previstos na tabela 3. Para obter o registro, o estabelecimento deverá obter matéria-prima de área florestal, própria ou de terceiro, cadastrada junto ao órgão ambiental competente.

O registro especial será concedido pelo Instituto Ambiental do Paraná, mediante requerimento da pessoa interessada, que deverá atender a alguns requisitos:

I- para o fornecedor de matéria-prima:

a) ter floresta explorada sob regime de manejo sustentado, autorizado e regularmente inscrito no órgão ambiental competente;

b) ter reflorestamento em área aprovada, mediante autorização e plano de corte e com manutenção de áreas de reserva legal e preservação permanente na propriedade.

II- para os estabelecimentos fabricantes, dispor de:

a) certificado de origem do produto;

b) instalações industriais adequadas ao tipo de atividade;

c) controle contínuo do fluxo de madeira na indústria;

d) meios de comprovar a regularidade ambiental da pessoa jurídica requerente ou detentora do registro especial e de seus sócios.

O pedido de registro do produto deverá ser protocolado junto ao escritório regional do Instituto Ambiental do Paraná (IAP), indicando o tipo de atividade a ser desenvolvida no estabelecimento e o produto final; apresentando dados sobre as instalações industriais, informando sua capacidade instalada 
de produção; fornecendo descrição detalhada dos produtos fabricados, informando forma, preço de venda ao consumidor e apresentação dos principais mercados consumidores; e apresentando a relação dos principais distribuidores atacadistas dos produtos, com indicação do nome empresarial. Deverá ainda ser apresentada a relação de todos os fornecedores de madeira e/ou, quando de produção própria, laudo de vistoria por profissional habilitado.

Após a concessão do registro, poderão ser feitas vistorias permanentes no estabelecimento. Quando de desativação da unidade industrial e/ou aquisição ou alienação de máquinas e equipamentos industriais que impliquem a alteração da capacidade de produção do estabelecimento, comunicar o órgão competente, para que proceda à vistoria do local.

O registro especial poderá ser cancelado pelo coordenador geral de fiscalização se, posteriormente à concessão, ocorrer o não atendimento dos requisitos que condicionaram a concessão do registro, ou a prática de conluio ou fraude, igualmente em casos de crime contra a ordem tributária, ou de qualquer outra infração decorrente do descumprimento de normas reguladoras da produção, importação e comercialização dos produtos, ou ainda entre fornecedor e beneficiador da madeira. Quando do cancelamento do registro especial, tem-se a apreensão do estoque de matérias-primas, produtos em elaboração, produtos acabados e materiais de embalagem existentes no estabelecimento, os quais poderão ser destinados às instituições que desempenhem função social.

Estão sujeitos ao selo de controle os artefatos de madeira de fabricação nacional destinados ao mercado interno, ou destinados à exportação, desde que sob rígido controle do órgão oficial competente.

Os produtos registrados não poderão sair dos estabelecimentos industriais, serem vendidos ou expostos à venda, mantidos em depósito fora dos referidos estabelecimentos, ainda que em armazéns gerais, ou ser liberados pelas repartições fiscais, sem que, antes, sejam selados.

Os artefatos sob controle deverão ser marcados antes da saída do produto do estabelecimento industrial, ou previamente à remessa para o exterior, no caso de produtos exportados, contendo as seguintes indicações:

I- classe de enquadramento, conforme estabelecido na tabela 3;

II- origem do produto;

III- data de fabricação do produto.

O selo de controle será colado em cada peça fabricada, utilizando-se, na selagem, adesivo que assegure seu dilaceramento quando da sua retirada do artefato.

A administração do selo de controle será efetuada em nível regional pelo Instituto Ambiental do Paraná. Em nível nacional, pela Receita Federal, a quem compete a supervisão e o controle da distribuição, guarda e fornecimento dos selos. Em nível local, pelos escritórios regionais do IAP, a quem compete proceder à fiscalização e controlar as requisições, bem assim adotar os procedimentos referentes à guarda, distribuição e fiscalização de seu uso.

O valor tributável para o cálculo do IPI devido será apurado da mesma forma que os outros produtos de madeira nacionais, tomando-se por base a alíquota determinada na tabela 3 .

Os móveis de madeira passam a ser distribuídos em quatro classes, observadas as seguintes regras para o respectivo enquadramento:

Classe I: móveis feitos de madeira oriunda de florestas plantadas com essências nativas com selo de origem;

Classe II: móveis feitos de madeira oriunda de florestas plantadas com essências nativas sem selo de origem.

Classe III: móveis feitos de madeira oriunda de florestas nativas manejadas com selo de origem;

Classe IV: móveis feitos de madeira oriunda de florestas nativas manejadas sem selo de origem;

Classe V: móveis feitos de madeira oriunda de florestas plantadas com essências exóticas com selo de origem;

Classe VI: móveis feitos de madeira oriunda de florestas plantadas com essências exóticas sem selo de origem.

Dentro do grupo de essências nativas, as alíquotas propostas variam de 2 a $100 \%$. O selo de origem permite sempre uma minoração do tributo, em qualquer classe de enquadramento, seja sobre florestas manejadas ou plantadas. O mesmo ocorre com as essências exóticas. Por outro lado, a ausência do selo de origem sempre acarreta uma majoração dos impostos sugeridos. Observa-se que a aplicação dessa metodologia produz um efeito compensatório entre os benefícios e a majoração. 
Tabela 3. Classe de enquadramento para móveis de madeira.

Table 3. Class of framework for wood furniture.

\begin{tabular}{lcccc}
\hline Tipo de selo & Classe de enquadramento & Cor do selo & $\begin{array}{c}\text { Alíquota } \\
\text { atual }\end{array}$ & $\begin{array}{c}\text { Alíquota } \\
\text { proposta }\end{array}$ \\
\hline Essencias nativas & I- Plantada com selo de origem & Verde-escuro & 5 & 4 \\
& II- Plantada sem selo de origem & Verde-claro & 5 & 6 \\
& III- Manejada com selo de origem & Roxo & 5 & 2 \\
& IV- Manejada sem selo de origem & Laranja & 5 & 10 \\
Essencias exóticas & V- Sem origem & Preto & 5 & 100 \\
& VI- Com selo de origem & Azul & 5 & 2 \\
\hline
\end{tabular}

\section{CONCLUSÕES}

- Uma alternativa promissora para incentivar o uso racional e o aumento da cobertura florestal com araucária no Paraná é a implementação de programas de incentivo tributário para a conservação e uso sustentado das florestas, eis que o Sistema Tributário Nacional permite e incentiva a aplicação da extrafiscalidade na busca do desenvolvimento econômico e social da nação. Na adoção de novos programas de incentivo fiscal, destinados ao desenvolvimento do setor florestal e à proteção do meio ambiente, é fundamental a realização de estudos de zoneamento ecológico-econômico por região, determinando quais regiões poderiam ser alvo de isenções e incentivos, e de que forma tais benefícios poderiam ser concedidos. Mais especificamente, sugere-se que a aplicação de uma alíquota progressiva para o Imposto sobre Transmissão de Bens Imóveis, em função da qualidade e tamanho do remanescente, pode ser uma eficaz ferramenta para a preservação do Bioma Florestal com Araucária no Paraná. Concomitantemente, a adoção de uma nova metodologia para o cálculo do valor do Imposto sobre Produtos Industrializados, exclusivo para artefatos de madeira, indubitavelmente forneceria subsídios para o desenvolvimento sustentável das florestas de araucária no Estado.

- Medidas de incentivo à conservação das florestas particulares e ao uso sustentável dos recursos madeireiros e não madeireiros, somadas ao instrumental atualmente utilizado, podem contribuir com maior efetividade na conservação e recuperação do Bioma Florestal com Araucária.

\section{REFERÊNCIAS}

BACHA, C. J. C. Análise custo-benefício dos programas federais de incentivo ao reflorestamento no Brasil. Piracicaba: Universidade de São Paulo, 1995. 88 p. Relatório de Pesquisa.

BALEEIRO, A. Direito tributário brasileiro. 11. ed. Atualização: Misabel Abreu Machado Derzi. Rio de Janeiro: Forense, 2002. 1063 p.

BASTOS, C. R. Curso de direito financeiro e de direito tributário. 5. ed. São Paulo: Forense, 1997.

CASTELANOS, A. H. P. Considerações sobre os impostos indiretos no Brasil frente a possível harmonização tributária no Mercosul: estudo do ICMS, ISS e IPI. Disponível em: <www.argumentum.com.br>.

FOERSTER, A. C. Perfil do sistema tributário brasileiro pós-Constituição Federal de 1988. Curitiba: IPARDES, 1991. 105 p.

MAACK, R. Geografia física do estado do Paraná. Curitiba: CODEPAR, 1968. 350 p.

NICHOLAS, J. A practitioner's guide to development impact fees. Chicago: American Planing Association, $1991.9 \mathrm{p}$

OSBORN, T. Lei agrícola e política conservacionista dos EUA. In: AGROANALYSIS. Washington: USDA/ERS, 1997. p. 11 - 15. 
PICHOT, F.; RAPADO, J. R. La fiscalidad y el medio ambiente: políticas complementarias. Madrid: Ediciones Mundi-Prensa, 1994. 118 p.

PINAZZO, J. Diagnóstico sobre el estado actual de los ecosistemas forestales en el Paraguay. In: CONFERENCIA DEL MERCOSUL - MEIO AMBIENTE E ASPECTOS TRANSFRONTEIRIÇOS, 1996, San Bernardino. Anais do... San Bernardino: Alter Vida, 1996. 77 p.

PLATERO, R. V. Evaluación de impacto del desarollo forestal en Uruguay. Montevideo: Sociedad de Productores Forestales, Asociación Rural del Uruguay, 1996. p. 1 - 13.

PRADO, A. C. Uma avaliação dos incentivos fiscais do FISET - Florestamento/Reflorestamento. In: Brasil Florestal, v. 17, n. 69, p. 3 - 26, 1990.

SANTOS, A. J. Os instrumentos fiscais da política florestal francesa. Revista Floresta, Curitiba, n. 25, p. $71-77,1997$.

VIEIRA, J. R. A regra matriz de incidência do IPI: texto e contexto. Curitiba: Juruá, 1993. 180 p.

YOUNG, E.; SHIELDS, D. A. New agricultural policy in USA. In: AGROANALYSIS. Washington: USDA/ERS, 1996. p. 19 - 24. 
FLORESTA, Curitiba, PR, v. 41, n. 3, p. 575-588, jul./set. 2011

Trevizam, R. et al. 